\title{
Dissociation of surface properties and "intrinsic" resistance to $\beta$ lactams in Pseudomonas aeruginosa
}

\author{
D. M. LIVERMORE and T. L. PITT* \\ Department of Medical Microbiology, The London Hospital Medical College, Turner Street, London E1 2AD \\ and "Division of Hospital Infection, Central Public Health Laboratory, 61 Colindale Avenue, Colindale, \\ London NW9 $5 H T$
}

\begin{abstract}
Summary. Carbenicillin resistance in strains of Pseudomonas aeruginosa isolated in Britain is mediated more frequently by "intrinsic factors" than by $\beta$-lactamase production. Intrinsically carbenicillin-resistant isolates almost invariably were more resistant to azlocillin, cefoperazone, cefotaxime, ceftazidime, chloramphenicol, tetracycline and nalidixic acid than were carbenicillin-susceptible strains. This crossresistance to different classes of antimicrobials suggested an impermeability-based mechanism of resistance, perhaps involving the outer membrane. The structure and composition of the outer membrane of the pseudomonas cell also influences the $\mathrm{O}$ serotype specificity and the susceptibility to many bacteriophages. We therefore examined these properties for possible relationships to antibiotic resistance. Carbenicillin-resistant (122) and -sensitive (127) $P$. aeruginosa strains from 24 hospitals were compared. Serotype O:1, O:3, O:6, O:10 and $O: 11$ strains predominated in both groups. Non-typable and polyagglutinating strains were infrequent in both groups. With one possible exception, none of 18 bacteriophages showed a significant preference for carbenicillin-resistant or -sensitive strains. Variation between strains was observed in the electrophoretic profile of LPS and this could be related in part to serotype, but not to antibiotic resistance. Our results contrast with those of earlier small-scale studies which have claimed relationships between surface properties and antibiogram in $P$. aeruginosa, and suggest that interpretation of the minor changes in LPS sometimes observed in association with the development of antibiotic resistance in vitro requires caution.
\end{abstract}

\section{Introduction}

In a large-scale survey Williams et al. (1984a and b) found that $c .10 \%$ of isolates of Pseudomonas aeruginosa from British hospitals were insensitive to carbenicillin (MIC $>128 \mathrm{mg} / \mathrm{L})$. Resistance was associated with production of carbenicillin-hydrolysing $\beta$ lactamases in $c .20 \%$ of these isolates but such enzymes were absent from the remainder. The resistance of the carbenicillinase non-producing strains was attributed to 'intrinsic' factors. Intrinsic resistance involved neither changes in chromosomal $\beta$-lactamase synthesis nor modification of the penicillin-binding proteins (PBPs) and was postulated to depend on cell impermeability.

The PBPs of $P$. aeruginosa are exposed in sphaeroplasts (Livermore, unpublished observations), so the exclusion of $\beta$-lactam compounds must involve

Received 29 Oct. 1985; accepted 20 Jan. 1986 a cell structure external to the cytoplasmic membrane, such as the intact outer membrane. Most small aqueous solutes cross this layer through aqueous pores composed of 'porin' proteins and, amongst enterobacteria, there is a close correlation between porin quantity, cell permeability and resistance to $\beta$ lactams (Nikaido and Vaara, 1985). In $P$. aeruginosa, however, the amount of porin protein is surprisingly large considering the low permeability of the organism (Angus et al., 1982; Hancock, 1984), and is undiminished in intrinsically-resistant strains (Livermore, 1984). To accommodate these observations, it is postulated that porin function in $P$. aeruginosa may be controlled by other outermembrane components including the lipopolysaccharide (LPS) (Angus et al., 1982; Kropinski et al., 1982). The overall assembly of the outer-membrane proteins and LPS also determines surface properties such as $O$ serotype and susceptibility to many 
bacteriophages and pyocins, raising the possibility that the antibiogram of strains and their surface properties may be related. Support for this hypothesis can be drawn from the many instances in which serotype, bacteriophage-susceptibility and LPSsugar changes have been associated with the development of resistance (and hypersensitivity) in laboratory mutants of $P$. aeruginosa Kropinski et al., 1982; Slack and Pitt. 1982; Darveau and Hancock, 1983; Godfrey et al., 1984; Meadow and Wells, 1985; Shearer and Legakis, 1985). However, the relationship of derived mutants to naturallyoccurring resistant strains is difficult to assess and, in the present study, we have compared the surface properties of large groups of carbenicillin-sensitive and -resistant $P$. aeruginosa isolates, with particular emphasis on the LPS components. Serotyping and phage-susceptibility tests were performed and extracted LPS was electrophoresed to estimate its heterogeneity in each strain.

\section{Materials and methods}

\section{Bacterial strains}

All cultures were obtained during a recent multicentre survey of antibiotic resistance in $P$. aeruginosa (Williams et al. 1984a). We received 131 isolates that were intrinsically resistant to carbenicillin (MIC $>128 \mathrm{mg} / \mathrm{L}$ ), i.e., they did not produce carbenicillin-hydrolysing $\beta$ lactamases, and 129 of these, from 22 hospitals, were examined in the present investigation. The intrinsic nature of their resistance was established previously (Williams et al., 1984b). The resistant strains were compared with a control sample of 130 randomly selected, carbenicillinsusceptible (MIC $\leqslant 64 \mathrm{mg} / \mathrm{L}$ ) $P$. aeruginosa isolates. This sample comprised four to six isolates from each of the 24 hospitals that participated in the survey. Organisms that had borderline sensitivity/resistance ( $\mathrm{MIC}=128 \mathrm{mg} / \mathrm{L}$ ) to carbenicillin were not examined.

\section{Bacteriophages}

The set of bacteriophages used for typing was 7, 16, 21 . 24, 31, 44, 68, 73, 109, 1214, F7, F8, F10, M4, Col.11, Col.18 and Col.21. For details of the phages, see Bergan (1975).

\section{Antibiotics}

Azlocillin was obtained from Bayer Pharmaceuticals, Haywards Heath, Surrey; carbenicillin from Beecham Research Laboratories, Brentford, Middlesex; cefoperazone from Pfizer Inc., Sandwich, Kent; cefotaxime and gentamicin from Rousell Laboratories Ltd, Wembley, Middlesex; ceftazidime from Glaxo Group Research,
Greenford, Middlesex; chloramphenicol from ParkeDavis and Co., Pontypool, Gwent; nalidixic acid from Sigma Chemical Co., St Louis MO, USA; and tetracycline from Lederle Laboratories, Poole, Dorset.

\section{Typing methods}

Cultures were serotyped by slide agglutination tests with the 17 antisera of the International Antigenic Typing Scheme (Liu et al., 1983). Additional antisera were prepared against the type strains of serotypes $\mathrm{O}: 2 \mathrm{a}$ and $\mathrm{O}: 2 \mathrm{~b}$ and $\mathrm{O}: 5 \mathrm{~d}$ (Vèron, 1961) and were used for the subdivision of serotypes O:2 and O:5 (Pitt, 1981). Bacteriophage typing was performed by the methods of Asheshov (1974).

\section{MIC determinations}

MICs of antibiotics were determined by a plate dilution method as described by Williams et al. (1984).

\section{Electrophoresis of LPS}

The method of Hitchcock and Brown (1983) was adapted to determine the profiles of LPS in crude extracts of whole cells of $P$. aeruginosa. Cultures were grown overnight at $37^{\circ} \mathrm{C}$ with continuous shaking in $10-\mathrm{ml}$ volumes of Antibiotic No. 3 Medium (Difco) and 1-ml volumes of these broths were used to inoculate $9 \mathrm{ml}$ of fresh, warm $\left(37^{\circ} \mathrm{C}\right)$ broth. After incubation at $37^{\circ} \mathrm{C}$ for 4h, 1.5-ml amounts were withdrawn and centrifuged at $10000 \mathrm{~g}$ for $1 \mathrm{~min}$ in an Eppendorf 5414 Microfuge. The pellet was blotted dry with tissue paper and resuspended in $75 \mu \mathrm{l}$ of solublisation buffer, consisting of sodium dodecyl sulphate $2 \% \mathrm{w} / \mathrm{v}, 2$-mercaptoethanol $4 \% \mathrm{v} / \mathrm{v}$, glycerol $10 \% \mathrm{v} / \mathrm{v}$ and bromophenol blue $0.01 \% \mathrm{w} / \mathrm{v}$ in $1.0 \mathrm{M}$ Tris- $\mathrm{HCl}$ buffer $p \mathrm{H} 6.8$. The suspensions were heated at $100^{\circ} \mathrm{C}$ for $10 \mathrm{~min}$. Subsequently, $50 \mu \mathrm{g}$ of proteinase $\mathrm{K}$ (Sigma) in $15 \mu \mathrm{l}$ of solublisation buffer was added and the suspensions were held overnight at $55^{\circ} \mathrm{C}$, then electrophoresed in the discontinuous polyacrylamide gel system of Laemmli (1970). The acrylamide and $\mathrm{NN}^{\prime}$ methylene bisacrylamide concentrations were adjusted to 13.5 and $0.25 \% \mathrm{w} / \mathrm{v}$, respectively, in the running gel, and to 6 and $0.6 \% \mathrm{w} / \mathrm{v}$, respectively, in the stacking gel. Sodium dodecyl sulphate was omitted from the running and stacking gel mixtures. Electrophoresis was performed at a constant current of $50 \mathrm{~mA} / \mathrm{gel}$ and LPS was visualised by silver staining (Tsai and Frasch, 1982).

\section{Statistical test}

The $\chi^{2}$ test was used to test the significance of differences in the serotype distributions and bacteriophage susceptibilities of the carbenicillin-resistant andsensitive groups of $P$. aeruginosa strains. 


\section{Results}

\section{Elimination of replicate organisms}

Both the carbenicillin-resistant and -sensitive groups of isolates appeared to contain some replicate cultures. These were defined as organisms from the same hospital that gave identical serotype reactions and antibiotic-susceptibility patterns and were indistinguishable by phage typing. We identified seven apparent replicates amongst the resistant organisms and three in the sensitive group, and these were excluded from further studies. Thus, 122 carbenicillin-resistant and 127 sensitive strains remained.

Susceptibility of carbenicillin-resistant and-sensitive strains to other antibiotics

The distributions of MICs of azlocillin, cefoperazone, cefotaxime, ceftazidime, nalidixic acid, chloramphenicol, tetracycline and gentamicin for both groups of strains are presented in table I. The carbenicillin-resistant organisms were more resistant than the sensitive group to all the other antibiotics tested except gentamicin. The only exceptions to this cross-resistance pattern were occasional carbenicillin-sensitive strains that were highly resistant to one or more of tetracycline, chloramphenicol and nalidixic acid.

Serotype distribution of resistant and sensitive isolates.

There was little association between antibiogram and $\mathrm{O}$ serotype (table II). The same serotypes $\mathrm{O}: 1, \mathrm{O}: 3, \mathrm{O}: 6, \mathrm{O}: 10$ and $\mathrm{O}: 11$ predominated in both the resistant and sensitive groups. Strains that reacted also with the polyvalent II antiserum pool were encountered at high frequency in each group. Many of these "group II" strains reacted specifically with one of the individual antisera contained in this pool (i.e., O:2a, O:2b, O:5 or $\mathrm{O}: 16$ ) and appear under these individual headings in table II,

Table I. Distribution of MICs of $\beta$-lactam and non- $\beta$-lactam antibiotics for carbenicillin-resistant and -sensitive $P$. aeruginosa

\begin{tabular}{|c|c|c|c|c|c|c|c|c|c|c|c|c|c|c|c|}
\hline \multirow[b]{2}{*}{ Antibiotic } & \multirow{2}{*}{$\begin{array}{c}\text { Group } \\
\text { of strains* }\end{array}$} & \multicolumn{14}{|c|}{ Number of strains for which $\mathrm{MIC}(\mathrm{mg} / \mathrm{L})$ was } \\
\hline & & $\leqslant 0 \cdot 125$ & $0 \cdot 25$ & 0.5 & 1 & 2 & 4 & 8 & 16 & 32 & 64 & 128 & 256 & 512 & $>512$ \\
\hline \multirow[t]{2}{*}{ Azlocillin } & $\mathrm{Cb}^{\mathrm{r}}$ & & & & & & & 1 & 33 & 71 & 14 & 2 & & & 1 \\
\hline & $\mathrm{Cb}^{\mathrm{s}}$ & & & & & 12 & 63 & 51 & 1 & & & & & & \\
\hline \multirow[t]{2}{*}{ Cefoperazone } & $\mathrm{Cb}^{\mathrm{r}}$ & & & & & & 4 & 6 & 78 & 33 & 3 & & & & \\
\hline & $\mathrm{Cb}^{\mathrm{s}}$ & & & & & 23 & 90 & 13 & 1 & & & & & & \\
\hline \multirow{2}{*}{ Cefotaxime } & $\mathrm{Cb}^{\mathrm{r}}$ & & & & & & & & 2 & 26 & 50 & 42 & 2 & & \\
\hline & $\mathrm{Cb}^{\mathrm{s}}$ & & & & & & 10 & 48 & 65 & 4 & & & & & \\
\hline \multirow[t]{2}{*}{ Ceftazidime } & $\mathrm{Cb}^{\mathrm{r}}$ & & & & & 35 & 53 & 30 & 4 & & & & & & \\
\hline & $\mathrm{Cb}^{\mathrm{s}}$ & & 3 & 27 & 87 & 9 & 1 & & & & & & & & \\
\hline \multirow[t]{2}{*}{ Nalidixic acid } & $\mathrm{Cb}^{\mathrm{r}}$ & & & & & & & & & 2 & 2 & 16 & 34 & 53 & 13 \\
\hline & $\mathrm{Cb}^{\mathrm{s}}$ & & & & & & & 1 & 1 & 19 & 92 & 5 & 3 & 1 & 2 \\
\hline \multirow[t]{2}{*}{ Tetracycline } & $\mathrm{Cb}^{\mathrm{r}}$ & & & & & & & 1 & 3 & 23 & 75 & 16 & & 2 & \\
\hline & $\mathrm{Cb}^{\mathrm{s}}$ & & & & & & 1 & 7 & 70 & 44 & 1 & & 1 & & \\
\hline \multirow[t]{2}{*}{ Chloramphenicol } & $\mathrm{Cb}^{\mathrm{r}}$ & & & & & & & & 1 & 2 & 7 & 11 & 48 & 45 & 6 \\
\hline & $\mathrm{Cb}^{\mathrm{s}}$ & & & & & & & 1 & 4 & 43 & 54 & 11 & 2 & 6 & 3 \\
\hline \multirow[t]{2}{*}{ Gentamicin } & $\mathrm{Cb}^{\mathrm{r}}$ & & 13 & 29 & 50 & 16 & 8 & & 2 & 2 & & & 2 & & \\
\hline & $\mathrm{Cb}^{\mathrm{s}}$ & & 3 & 51 & 52 & 20 & 1 & & & & & & & & \\
\hline
\end{tabular}

${ }^{*} \mathrm{Cb}^{\mathrm{r}}=$ carbenicillin resistant; $\mathrm{Cb}^{\mathrm{s}}=$ carbenicillin sensitive. 
Table II. Serotypes of carbenicillin-resistant and -sensitive P.aeruginosa

Number (percentage) of strains of each serotype in

Serotype Resistant group (122) Sensitive group (127)

\begin{tabular}{|c|c|c|}
\hline 1 & $5(4 \cdot 1)$ & $12(9 \cdot 4)$ \\
\hline $2 a$ & $1(0.8)$ & $1(0 \cdot 8)$ \\
\hline $2 b$ & $0(0)$ & $3(2 \cdot 4)$ \\
\hline 3 & $9(7 \cdot 4)$ & $13(0 \cdot 2)$ \\
\hline 4 & $3(2 \cdot 5)$ & $4(3 \cdot 1)$ \\
\hline $5 \mathrm{~d}$ & $5(4 \cdot 1)$ & $2(1 \cdot 6)$ \\
\hline 6 & $31(25 \cdot 4)$ & $35(27 \cdot 5)$ \\
\hline 7 & $2(1 \cdot 6)$ & $0(0)$ \\
\hline 8 & $2(1 \cdot 6)$ & $4(3 \cdot 1)$ \\
\hline 9 & $5(4 \cdot 1)$ & $3(2 \cdot 4)$ \\
\hline 10 & $18(14 \cdot 8)$ & $15(11 \cdot 8)$ \\
\hline 11 & $18(14.8)$ & $9(7 \cdot 1)$ \\
\hline 13 & $0(0)$ & $2(1 \cdot 6)$ \\
\hline 16 & $4(3 \cdot 3)$ & $8(6 \cdot 3)$ \\
\hline Pool* I & $1(0 \cdot 8)$ & $0(0)$ \\
\hline II & $4(3 \cdot 3)$ & $4(3 \cdot 1)$ \\
\hline IV & $0(0)$ & $1(0 \cdot 8)$ \\
\hline PAt & $9(7 \cdot 4)$ & $6(4 \cdot 7)$ \\
\hline $\mathrm{NT}_{\ddagger}^{+}$ & $5(4 \cdot 1)$ & $5(3.9)$ \\
\hline
\end{tabular}

* Agglutinated by antiserum pool, not by any individual antiserum.

$+\mathrm{PA}=$ polyagglutinating, i.e., agglutinated by 2 or more unrelated antisera.

$\$ N T=$ not typable, i.e., not agglutinated by any antiserum.

but some strains failed to react with these sera and were classified as $\mathrm{O}$ :II. Serotype O: 1 strains were twice as frequent in the sensitive group as in the resistant group and serotype $0: 11$ strains were encountered twice as frequently in the resistant group but in neither case was this difference statistically significant ( $p>0.05: \chi^{2}$ tests). Non-typable organisms (not agglutinated by any antiserum tested) and polyagglutinating strains (agglutinated by two or more antisera to unrelated serotypes) were encountered with equal infrequency in both the carbenicillin-resistant and-sensitive groups.

\section{Lysis of carbenicillin-resistant and-sensitive P. aeru- ginosa by bacteriophages}

With the exception of phage Col. 21, none of the phage was significantly more or less active on carbenicillin-resistant or -sensitive strains ( $p>0.05$; $\chi^{2}$ tests, table III). Statistical analysis did suggest that Col.21 was more often lytic for carbenicillin-
Table III. Susceptibility of P.aeruginosa strains to bacteriophages

\begin{tabular}{lcc}
$\begin{array}{l}\text { Phage } \\
\text { no. }\end{array}$ & $\begin{array}{c}\text { Number (percentage) of Number (percentage) of } \\
\text { carbenicillin-resistant } \\
\text { strains lysed (122) }\end{array}$ & $\begin{array}{c}\text { carbenicillin-sensitive } \\
\text { strains lysed (127) }\end{array}$ \\
\hline 7 & $40(32 \cdot 8)$ & $4434 \cdot 6)$ \\
16 & $12(9 \cdot 8)$ & $16(12 \cdot 6)$ \\
21 & $34(27 \cdot 9)$ & $36(28 \cdot 3)$ \\
24 & $24(19 \cdot 6)$ & $18(14 \cdot 2)$ \\
31 & $10(8 \cdot 2)$ & $11(8 \cdot 7)$ \\
44 & $34(27 \cdot 9)$ & $49(38 \cdot 6)$ \\
68 & $47(38 \cdot 5)$ & $58(45 \cdot 7)$ \\
73 & $11(9 \cdot 0)$ & $6(4 \cdot 7)$ \\
F7 & $10(8 \cdot 2)$ & $8(6 \cdot 3)$ \\
F8 & $28(23 \cdot 0)$ & $38(30 \cdot 0)$ \\
F10 & $2(1 \cdot 6)$ & $3(2 \cdot 4)$ \\
109 & $43(35 \cdot 2)$ & $46(36 \cdot 2)$ \\
352 & $26(21 \cdot 3)$ & $31(24 \cdot 4)$ \\
1214 & $45(36 \cdot 9)$ & $62(48 \cdot 8)$ \\
M4 & $18(14 \cdot 8)$ & $27(21 \cdot 3)$ \\
Col. 21 & $2(1 \cdot 6)$ & $11(8 \cdot 7)$ \\
Col. 11 & $35(28 \cdot 7)$ & $40(31 \cdot 5)$ \\
Col. 18 & $7(5 \cdot 7)$ & $10(7 \cdot 9)$ \\
\hline
\end{tabular}

sensitive organisms than for carbenicillin-resistant strains ( $p<0.05>0.01 ; \chi^{2}$ test) but we are cautious of this result because of the small total number of strains lysed by this bacteriophage (13 out of 249 strains tested).

Some relationship was apparent between the serotypes of strains and their bacteriophage-susceptibility. Strains of serotypes $\mathrm{O}: 3, \mathrm{O}: 6$ and $\mathrm{O}: 9$ generally were susceptible to five or more bacteriophages, whereas the mean numbers of lytic reactions with strains of serotypes $\mathrm{O}: 10$ and $\mathrm{O}: 11$ and with non-typable strains were three or fewer.

\section{Typing of highly resistant organisms}

The typing results with the most resistant $P$. aeruginosa strains (carbenicillin MIC $\geqslant 1024 \mathrm{mg} / \mathrm{L}$ ) were analysed separately (table IV). Eight strains fell within this category; they exhibited a diverse scatter of serotypes and bacteriophage susceptibilities. Five $(63 \%)$ of these strains were lysed by bacteriophage 7 compared with only 40 out of 122 $(32.8 \%)$ and 44 out of $127(34.6 \%)$ of the whole resistant and sensitive groups, respectively.

\section{Electrophoresis of LPS}

Studies in our laboratories have shown that the LPS profiles obtained with $P$. aeruginosa by the 
Table IV. Serotypes and phage sensitivity of highly carbenicillinresistant $P$.aeruginosa strains

\begin{tabular}{|c|c|c|c|c|}
\hline $\begin{array}{l}\text { Strain } \\
\text { no. }\end{array}$ & Source & Serotype & $\begin{array}{c}\text { Carbenicillin MIC } \\
(\mathrm{mg} / \mathrm{L})\end{array}$ & $\begin{array}{l}\text { Bacteriophage } \\
\text { causing lysis }\end{array}$ \\
\hline M76 & Aberdeen & $\mathrm{O}: 11$ & 2048 & 1214 \\
\hline M642 & Edinburgh & $0: 6$ & 1024 & 7, 24, M4, Col.11 \\
\hline M917 & Harlow & $0: 5 \mathrm{~d}$ & 1024 & None \\
\hline M1251 & Liverpool & $0: 9$ & 1024 & $7,21,24,68$ \\
\hline M1426 & Nottingham & $0: 1$ & $>2048$ & 7 \\
\hline M1499 & Nottingham & $0: 11$ & $>2048$ & $\begin{array}{l}\text { 7, 44, F8, 109, } \\
\text { 1214, M4, Col.11 }\end{array}$ \\
\hline M2566 & Nottingham & P.A. & 2048 & None \\
\hline M2012 & London & $0: 3$ & 1024 & $\begin{array}{l}7,21,24,44,68, \\
\text { F8, 109, 352, 1214, } \\
\text { Col.11 }\end{array}$ \\
\hline
\end{tabular}
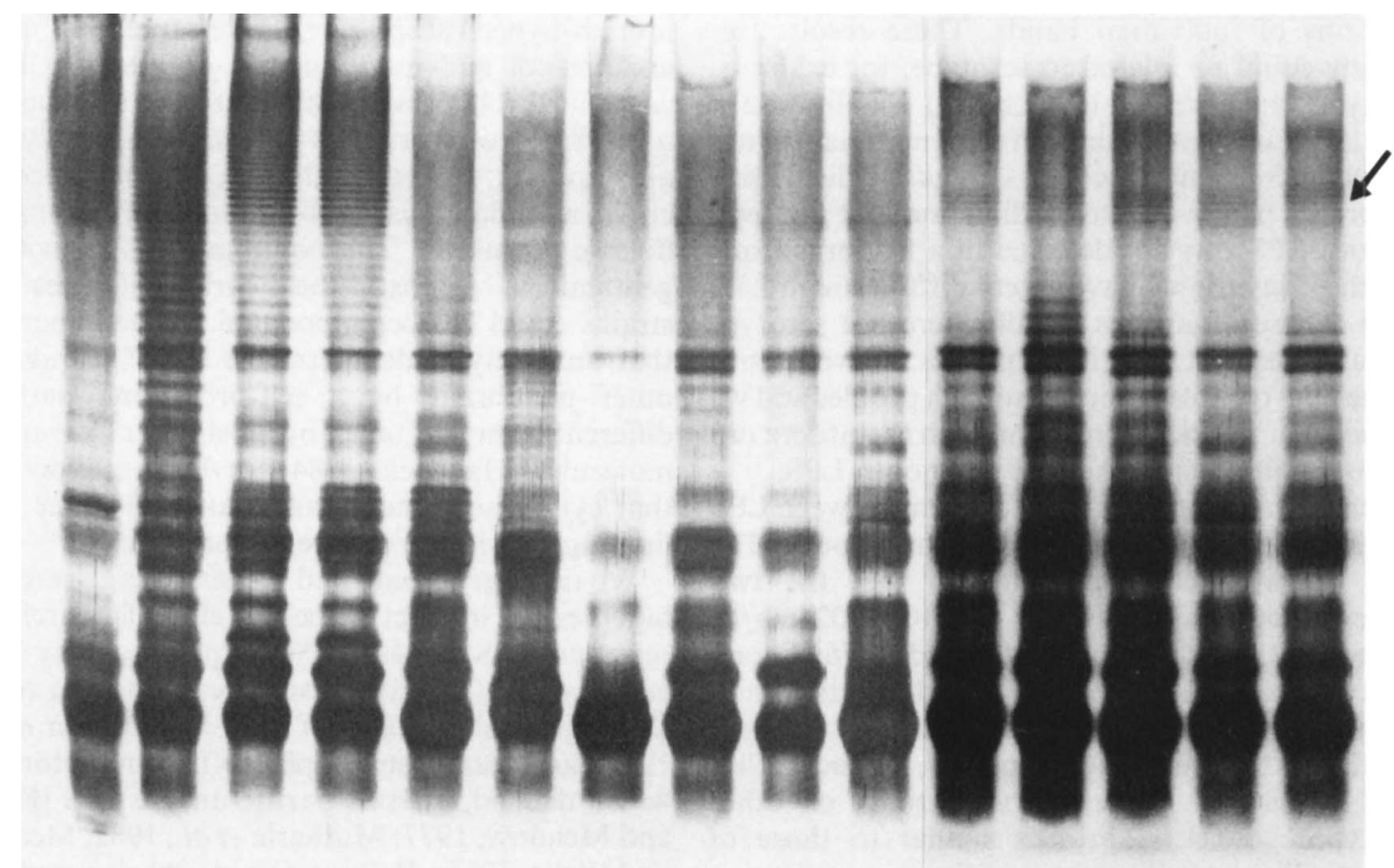

\section{$\begin{array}{lllllllllllllll}1 & 2 & 3 & 4 & 5 & 6 & 7 & 8 & 9 & 10 & 11 & 12 & 13 & 14 & 15\end{array}$}

Figure. Electrophoretic profiles of LPS from carbenicillin-sensitive and -resistant P.aeruginosa. Tracks 1-6 contain LPS from serotype O: 11 strains with carbenicillin MICs as follows: (1) strain M825, MIC $32 \mathrm{mg} / \mathrm{L}$; (2) strain M921, MIC 32 mg/L; (3) strain M346, MIC $256 \mathrm{mg} / \mathrm{L}$; (4) strain M307, MIC $512 \mathrm{mg} / \mathrm{L}$; (5) strain M1499, MIC > $2048 \mathrm{mg} / \mathrm{L}$; (6) strain M76, MIC 2048 mg/L. Tracks 7-10 contain LPS from serotype O: 1 strains as follows: (7) strain M1413, MIC <16 mg/L; (8) strain M918, MIC 32 mg/L; (9) strain M804, MIC $256 \mathrm{mg} / \mathrm{L}$; (10) strain M1426, MIC> $2048 \mathrm{mg} / \mathrm{L}$. Tracks 11-15 contain LPS from serotype O:3 strains as follows: (11) strain M1718, MIC $64 \mathrm{mg} / \mathrm{L}$; track (12) strain 512, MIC $64 \mathrm{mg} / \mathrm{L} ;$ (13) strain 654, MIC $256 \mathrm{mg} / \mathrm{L}$ (14) strain M85, MIC 512 mg/L; (15) strain M2102, MIC $1024 \mathrm{mg} / \mathrm{L}$. The intermediate mol. wt bands typical of serotype O: 3 are arrowed. 
method of Hitchcock and Brown (1983) are identical to those for LPS purified from the same strain by the procedure of Darveau and Hancock (1983). The profiles revealed a large low-mol. wt band, which sometimes appeared as a doublet, above which was a more or less extensive ladder of higher-mol. wt bands (figure). Results of this type are interpreted usually as indicating that the LPS within the strain is micro-heterogeneous in respect of the number of repeating $\mathrm{O}$-antigenic sugar subunits attached to the core oligosaccharide-lipid A component (Palva and Mansera, 1980; Hitchcock and Brown). The low-mol. wt band corresponds to rough LPS, composed of core oligosaccharide-lipid A but devoid of the repeating $\mathrm{O}$-antigenic subunits, whereas the ladder is given by smooth LPS forms with various numbers of $\mathrm{O}$-antigenic subunits attached to the lipid A-core oligosaccharide component. The smooth forms with the greatest number of subunits migrate the shortest distance and form the top-most bands of the ladder.

The prominence of the ladder varied between strains, both quantitively and in terms of the positions of individual bands. These results frequently could be related to serotype; for example, serotype $0: 11$ strains (tracks 1-6) usually had a very large amount of smooth LPS material (figure 3 ), and $\mathrm{O}: 3$ strains (tracks 11-15) gave a distinctive pattern of bands of intermediate mol. wt (arrow). Smooth LPS was not detected in a few organisms and these invariably gave a very diffuse rough LPS band. These organisms usually were not serotypable and were not sensitive to phages. However, not all the non-typable strains gave such profiles and we deduce that the lack of reaction with $\mathrm{O}$-antisera did not invariably reflect the lack of smooth LPS.

Very little correlation was apparent between LPS profile of strains and resistance to antibiotics. The only noteworthy association was that the two carbenicillin-highly-resistant (MIC $>1024 \mathrm{mg} / \mathrm{L}$ ) serotype O:11 strains (M1499 and M76; figure, tracks 5 and 6 respectively) lacked the highest mol. wt smooth LPS forms that were usually so characteristic of this serotype (figure 3). Carbenicillinhighly resistant $P$. aeruginosa strains of other serotypes gave LPS profiles similar to those of carbenicillin-sensitive strains of the same serotypes as shown by serotype $O: 1$ strains (tracks $7-10$ ) and by $\mathrm{O}: 3$ strains (tracks 11-15).

\section{Discussion}

Williams et al. (1984a and $b$ ) found that carbenicillin resistance in $P$. aeruginosa was determined most frequently by intrinsic factors and not by $\beta$ - lactamase. Representative intrinsically-resistant strains later were shown to have penicillin-binding proteins with unaltered affinity for $\beta$ lactams, and it was suggested that their insensitivity may have been due to reduced permeability. This was not determined by decreased porin expression (Livermore, 1984) but may have reflected porin regulation by other outer-membrane components such as the LPS. We therefore examined LPS-related surface properties in large groups of distinct carbenicillinresistant and -sensitive $P$. aeruginosa strains for possible relationships to antibiogram. Intrinsicallyresistant strains almost invariably had unusually high levels of resistance to tetracycline, chloramphenicol and nalidixic acid, as well as reduced susceptibility to other antipseudomonal $\beta$-lactam compounds, and this was taken to suggest a nonspecific, impermeability-based mechanism. Involvement of $\beta$ lactamase in their resistance had been discounted previously (Williams et al., 1984b). A similar cross-resistance profile is observed in $n a$ l $\mathrm{B}$ laboratory mutants obtained under selection pressure with nalidixic acid (Rella and Haas, 1982) and a cross-hypersusceptibility to tetracyclines, chloramphenicol and quinolones is observed in some carbenicillin-hypersusceptible strains (Noguchi et al., 1980; Livermore, 1984). It seems unlikely that any specific target modification simultaneously could modulate susceptibility to such a range of diverse chemicals. The continued full activity of gentamicin against the carbenicillin-resistant strains could be accommodated by the hypothesis that aminoglycosides permeate the $P$. aeruginosa outer membrane by a self-promoting pathway different from that taken by most other hydrophilic molecules (Hancock, 1984), or by the hypothesis that cytoplasmic-membrane transport is the ratelimiting step in the uptake of gentamicin.

We used serotyping and bacteriophage-susceptibility tests as indirect probes of cell-surface architecture and LPS structure. Serotype specificity in $P$. aeruginosa relates to the sugar composition of the O-antigenic side chains of the LPS (Chester et al., 1973), and many bacteriophages have receptor sites which depend, at least partly, on the LPS (Koval and Meadow, 1977; Mutharia et al., 1982; Meadow and Wells, 1985). Polyacrylamide gel electrophoresis was used to obtain direct profiles of the LPS and to examine the relative amounts of rough and smooth material in each strain.

Little correlation was detected between the surface architecture, as elucidated by these methods, and intrinsic resistance to antibiotics, even when only the most highly resistant organisms were considered. A wide range of serotypes was observed 
amongst the resistant strains and the prelevance of individual types did not vary significantly between the carbenicillin-resistant and-sensitive groups. Similarly, no significant differences were observed between the susceptibility of carbenicillin-resistant and -sensitive strains to lysis by various bacteriophages except possibly by Col. 21 . Nor, in general, did the relative amounts of smooth and rough LPS present in the cells differ between the resistant and sensitive strains. We do not afford great significance to the absence of high mol. wt smooth LPS forms from the two highly resistant O: 11 strains M76 and M1499. Highly resistant strains of other serotypes had LPS which was indistinguishable from that of sensitive strains of the same serotype, and other investigators have asociated lack of high mol. wt LPS forms with hypersusceptibility to $\beta$-lactam and other antibiotics (Koval and Meadow, 1977; Darveau and Hancock, 1983).

Our findings contrast with those obtained in a sixcentre study undertaken in Greece, where it was observed that carbenicillin-resistant $P$. aeruginosa strains that did not produce carbenicillinase generally were agglutinated by pooled antisera to serotypes $O: 2, O: 5, O: 15$ and $O: 16$ but not by any individual antiserum (Legakis et al., 1982). Carbenicillin-sensitive isolates from the same hospitals gave widely diverse serotype reactions. Intrinsically carbenicillin-resistant isolates from the Greek hospitals also were reported by Shearer and Legakis (1985) not to be lysed by bacteriophages $16,44,109$ and F8, which these authors considered to be specific for smooth LPS. Other groups, e.g., Meadow and Wells (1985), believe that phage 109 has a receptor site determined by the core oligosaccharide. These findings may indicate a basic difference in the types of intrinsic carbenicillin resistance prevelant in $P$. aeruginosa from Britain and Greece. It is noted, in this context, that the carbenicillin-resistant isolates from Greece were often cross-resistant to gentamicin.

It is also interesting to compare our findings

\section{REFERENCES}

Angus B L, Carey A M, Caron D A, Kropinski A M B, Hancock R E W 1982 Outer membrane permeability in Pseudomonas aeruginosa: comparison of a wild-type with an antibiotic-supersusceptible mutant. Antimicrobial Agents and Chemotherapy. 21:299-309.

Asheshov E H 1974 An assessment of the methods used for typing strains of Pseudomonas aeruginosa. In: Arseni A (ed) Proceedings of the sixth national congress of bacteriology. Leontiadi Medical Editions, Athens. pp 9-22.

Bergan T 1975 Epidemiological typing of Pseudomonas aerugi- regarding the surface architecture of naturallyoccurring carbenicillin-resistant $P$. aeruginosa with the results of studies performed on strains which developed $\beta$-lactam resistance in the laboratory. Loss of O-serotype determinants and phage receptors during the selection of cefsulodin resistance in $P$. aeruginosa was described by Slack and Pitt (1982) and increased carbenicillin resistance was observed in several $P$. aeruginosa mutants selected for resistance to phage 16 by Shearer and Legakis (1985). Neither of these associations was observed in the naturally-occurring resistant strains, where nontypability was as rare as in sensitive isolates and where bacteriophage 16 lysed similarly small numbers of resistant (12 out of 122) and sensitive (16 out of 127) strains. Using ethyl methane sulphonate mutagenesis, Godfrey et al. (1984) obtained four different types of $P$. aeruginosa mutants that had altered LPS sugar composition in association with impermeability-mediated $\beta$-lactam resistance. However, none of these mutants showed the increased resistance to chloramphenicol and tetracycline that was typical of the naturally-occurring carbenicillin-resistant strains.

Our findings do not disprove the involvement of the LPS in regulating antibiotic uptake in $P$. aeruginosa. Changes in the unexposed core oligosaccharide-lipid A region of the LPS could be envisaged that might be significant in regulating porin function without changing those surface properties of the cell that were examined in the present study. Our results do, however, reveal the great diversity of surface properties and LPS types present in the naturally-occurring resistant strains and caution against affording general significance to minor changes in LPS that may be observed concommitantly with the development of resistance in vitro.

D.M.L. is indebted to the Wellcome Trust for support (Grant no. 13445/I5).

nosa. In: Brown M R W (ed) Resistance of Pseudomonas aeruginosa. John Wiley and Sons, London, pp. 189-235.

Chester I R, Meadow P M, Pitt T L 1973 The relationships between the $\mathrm{O}$-antigenic lipoplysaccharides and serological specificity in strains of Pseudomonas aeruginosa of different O-serotypes. Journal of General Microbiology 78:305-318.

Darveau R P, Hancock R E W 1983 Procedure for isolation of bacterial lipopolysaccharides from both smooth and rough Pseudomonas aeruginosa and Salmonella typhimurium strains. Journal of Bacteriology 155:831-838.

Godfrey A J, Hatlelid L, Bryan L E 1984 Correlation between 
lipopolysaccharide structure and permeability resistance in $\beta$-lactam-resistant Pseudomonas aeruginosa. Antimicrobial Agents and Chemotherapy 26:181-186.

Hancock R E W 1984 Alterations in outer membrane permeability. Annual Review of Microbiology 38:237-264.

Hitchcock P J, Brown T M 1983 Morphological heterogenicity among Salmonella lipopolysaccharide chemotypes in silver stained polyacrylamide gels. Journal of Bacteriology 154:269-277.

Koval S F, Meadow P M 1977 The isolation and characterization of lipopolysaccharide-defective mutants of Pseudomonas aeruginosa PAC1. Journal of General Microbiology 98:387398.

Kropinski A M, Kuzio J, Angus B L, Hancock, R E W 1982 Chemical and chromatographic analysis of lipopolysaccharide from an antibiotic-supersusceptible mutant of Pseudomonas aeruginosa. Antimicrobial Agents and Chemotherapy 21:310-319.

Laemmli U K 1970 Cleavage of structural proteins during the assembly of the head of bacteriophage T4. Nature 227:680685 .

Legakis N J, Aliferopoulou M, Papavassiliou J, Papapetropoulou M 1982 Serotypes of Pseudomonas aeruginosa in clinical specimens in relation to antibiotic susceptibility. Journal of Clinical Microbiology 16:458-463.

Liu P V, Matsumoto H, Kusama H, Bergan T 1983 Survey of heat stable. major somatic antigens of Pseudomonas aeruginosa. International Journal of Systematic Bacterio$\log$ y3: $256-264$.

Livermore D M 1984 Penicillin-binding proteins, porins and outer-membrane permeability of carbenicillin-resistant and -susceptible strains of Pseudomonas aeruginosa. Journal of Medical Microbiology 18: 261-270.

Meadow P M, Wells P L 1985 Antibiotic sensitivity in lipopolysaccharide defective mutants of Pseudomonas aeruginosa. In: Daikos G K Giamarellou H (eds) Fourth Mediterranean congress of chemotherapy: Proceedings. Chemioterapia 4 (Suppl): 5-7.

Mutharia L M, Nicas T I. Hancock R E W 1982 Outer membrane proteins of Pseudomonas aeruginosa serotype strains. Journal of Infectious Diseases 146:770-779.
Nikaido H, Vaara M 1985 Molecular basis of bacterial outer membrane permeability. Microbiological Reviews 49:1-32.

Noguchi H, Fukasawa M, Komatsu T, Iyobe S, Mitsuhashi S 1980 Isolation of two types of Pseudomonas aeruginosa mutants highly sensitive to a specific group of beta-lactam antibiotics and with defect in penicillin-binding proteins. Journal of Antibiotics 33:1521-1526.

Palva E T, Mäkelä P H 1980 Lipopolysaccharide heterogeneity in Salmonella typhimurium analyzed by sodium dodecyl sulfate/polyacrylamide gel electrophoresis. European Journal of Biochemistry 107:137-143.

Pitt T L 1981 A comparison of flagellar typing and phage typing as means of subdividing the $\mathrm{O}$ groups of Pseudomonas aeruginosa. Journal of Medical Microbiology 14:261-270.

Rella M, Haas D 1982 Resistance of Pseudomonas aeruginosa PAO to nalidixic acid and low levels of B-lactam antibiotics: mapping of chromosomal genes. Antimicrobial Agents and Chemotherapy 22:242-249.

Shearer B G, Legakis N J, 1985 Pseudomonas aeruginosa: evidence for the involvement of lipopolysaccharide in determining outer membrane permeability to carbenicillin and gentamicin. Journal of Infectious Diseases 152:351355.

Slack M P E, Pitt T L 1982 Characterization of cefsulodinresistant variants of Pseudomonas aeruginosa. Journal of Antimicrobial Chemotherapy 9:111-117.

Tsai C M, Frasch C E 1982 A sensitive silver stain for detecting lipopolysaccharides in polyacrylamide gels. Analytical Biochemistry 119:115-119.

Véron M 1961 Sur l'agglutination de Pseudomonas aeruginosa: subdivision des groupes antigéniques $\mathrm{O}: 2$ et $\mathrm{O}: 5$. Annales de L'Institut Pasteur 101:456-460.

Williams R J, Lindridge M A. Said A A, Livermore D M, Williams J D 1984a National survey of antibiotic resistance in Pseudomonas aeruginosa. Journal of Antimicrobial Chemotherapy 14:9-16.

Williams R J, Livermore D M, Lindridge M A, Said A A, Williams J D 1984b Mechanisms of beta-lactam resistance in British isolates of Pseudomonas aeruginosa. Journal of Medical Microbiology 17:283-293. 